\title{
Social Media and Its Impact on Arab Youth Identity
}

\author{
Maha Ali Alshoaibi \\ Correspondence: Maha Ali Alshoaibi, Communication Department, Faculty of Communication, King Abdulaziz \\ University, 21589 P.O. Box 80200 Jeddah, Kingdom of Saudi Arabia.
}

Received: November 7, 2018

doi:10.5539/res.v11n1p1
Accepted: December 6, 2018 Online Published: December 26, 2018

URL: https://doi.org/10.5539/res.v11n1p1

\begin{abstract}
Through the analysis of influences from social networking sites surrounding the revolts of the Arab Spring, this paper seeks to evaluate about how the identity of Middle Eastern youth has been shaped by social media, and what future impact it could have on Middle Eastern social and political spheres. This paper relies on two key theories of the development of identity and self-perception - Social Cognitive Theory by Albert Bandura (1986) and Social Comparison theory by Festinger (1954). The paper shall try to make some unique contribution towards understanding the role that social media plays in transforming Arab youth identity, and its socio-political impact.
\end{abstract}

Keywords: social media, Arab youth, Arab spring, identity, social cognition, social comparison

\section{Background and Objectives of Study}

The use of social media amongst the youth has become a global phenomenon. With the people of the Middle-east operating as one of the most rapid adopters of social media and social networking sites, the functions and subsequent analysis these sites play hold critical influence in both social developments and political revolutions. It has been noted by scholars that the youth of the region played the most significant role in the Arab Spring revolutions (Anderson, 2011). It is evident that social media usage has been most swiftly and widely adopted by the same segment of the Arab society (Mourtada \& Salem, 2012). Existing literature surrounding the influence of social media throughout the Middle-east has been limited to the role it played in enabling coordination of protests and disseminating news to the international community. This paper seeks to evaluate the influence that these sites may have had on the revolts that have been a part of the Arab Spring. In addition, the question of social media's role and significance in the revolution naturally arises; this paper will seek to analyze what impact it could have on the Middle-eastern social and political spheres in the future. However, how the identity of the youth, the major adopters of the Social Networking Services (SNS), has been shaped by such media is an area that this paper would focus on more.

The influence of social media on 'youth identity' in the Middle-east is a fairly unexplored topic. Middle-eastern youth are different, almost unique, in their cultural, religious and societal make up. Currently literature exists surrounding the broader impact of media on youth but is primarily focused around Western nations encompassing starkly different population dynamics. While youth in the Western countries have been born and raised in nations that are governed by democratic administrations, Arab youth has lived under monarchies and dictatorial regimes. The Western countries have more liberalized societies when compared to communities in the Arab region (DeLong-Bas, 2014). Concepts such as freedom of speech and gender equality are fairly new in the Middle-eastern region while have a long-standing tradition in the West. As such, the Arab youth should, ideally, have been acclimatized to non-democratic governments and conservative society (Fitouti, 2011). However, the Arab Spring revolutions brought to the forefront a radical shift in the preferences, expectations and demands of the Arab youth, which, in turn, reveals a shift in youth identity.

It is noteworthy that the widespread adoption of social media occurred around the same period as the vociferous discontent towards governments shown by the Arab youth. As such, the question arises; did social media play a role in altering Arab youth identity, thereby having a greater influence on the Arab Spring revolutions than the mere medium of communication it has been portrayed to be by existing research? This paper seeks to offer insight into this inquiry through the combined analysis of social media impacts on Arab youth identity and its corresponding socio-political impacts.

In order to evaluate the influence of social media on Arab youth identity, this paper relies on two key theories of the development of identity and self-perception. The Social Cognitive Theory by Albert Bandura (1986) and the Social Comparison theory by Festinger (1954) have been used extensively to analyze the impact of mass media and communications on consumers. Also, there are studies that specifically concentrate on the effects of social media on its users, employing each of the two theories under consideration. However, the unique aspect of Arab youth identity and its relationship to social media is yet to be investigated through the lens of these theories. Also included in this paper are 
several studies which have been actively researching the influences from social media, using the perspective of social cognition and comparison. Youth is a time when identities are still volatile and vulnerable to changes. As such, based on the effectiveness of the two theories in studying the influence of mass media as well as well social media, the Social Cognition and Social Comparison would be excellent mediums of evaluating the impact of social media on Arab youth identity.

Notable recent developments in technology have spurred immense growth in the use of social media platforms across various parts of the world. The Middle-east occurs as one of the contexts around the globe that have been impacted in a significant way by the development and growth of social media (Howard \& Hussain, 2013, p. 18). Data from researches carried out in the recent past indicate that the commonly utilized social media platforms in the Middles-east are Twitter, Facebook, and LinkedIn. Nonetheless, the use of these media platforms varies across different countries in this part of the world. Precisely, Facebook seems to have penetrated the Middle-eastern countries than any other social media platform. While much has been hypothesized regarding the many impacts of social media amongst different population segments, the influence that social media has had is unique.

As previously mentioned, the growth of social media has had an impact on the Middle-east in a number of ways. More importantly, the evolution of social media across various countries has made people from these countries yearn for change with regard to their ways of life. Precisely, social media platforms have played a comprehensive role in influencing change (Stewart, 2012, p. 10) whereby people have become more empowered than they were before. Worth noting is the fact that social media platforms have provided an avenue in which the people can share ideas pertaining to issues that affect them on a daily basis. Through such sharing of ideas, the people of these countries have become more tolerant despite their ideological differences. Overall, social media has influenced change in the Middle-east in that it has empowered them to become more open and tolerate differing points of views held by people of varying ethnic and religious origins.

In some instances, social media has revealed an impact on some countries through its evolution as a representative voice of the country's constituents. Previously, social media has served as a platform for users to express their concerns, especially surrounding political and governmental issues. This convention has promoted a democratic forum for people in light of historical dictatorships, which might have otherwise destined them as victims. As a direct application of this effect, specific social media outlets (such as Facebook and Twitter) have catalyzed the decline of Middle-eastern administrations which failed to understand and sympathize with issues affecting their respective populaces (Nabi \& Oliver, 2009, p. 24). Events such as these demonstrate the dramatic potential of social media platforms and the degree of success which can be obtained in the political and governmental realms. In addition, corresponding revolutions incited from such events typically seek to bolster democratic elements within their respective countries, justifying the positive correlation between both social media and democracy among the encompassed population. However, these insights do not reveal whether social media has influenced the individual desires amongst such populations to employ a democratic government.

Another notable impact that social media has had on the Middle-east aligns with the fact that it has resulted in a slight change in gender roles. Notably, populations emanating from this part of the world are conservative in nature. They come from societies that are majorly segregated based on gender. However, social media platforms have instilled liberal views on these populations and this has resulted in a change of gender roles. In particular, social media platforms have enlightened people, particularly women. Such enlightening has resulted in the provision of more opportunities for women. This is contrary to the past whereby women were often oppressed and given discriminatory roles. In addition, social media has enlightened Middle-eastern women to become agents of change in their communities. This has resulted in provision of more leadership opportunities for women (Sakr, 2004, p. 20), contrary to the past whereby women were not allocated such roles.

Certainly, the growth of social media offers immense opportunities for the growth of businesses across various contexts. In one instance, social media has exhibited alluring opportunities for improving marketing schemes of a variety of business endeavors. Ultimately, this has contributed to an increase in dividends of participating business, which is tightly coupled to the subsequent boost in economy. With regard to this, different countries in the Middle-east have enjoyed significant prosperity proportional to the expansion of various social media channels. Such impacts can be observed in countries including the United Arab Emirates, which continue to benefit from the incorporation of social media through individual corporations and institutions. These enterprises also profit from secondary advantages of these platforms, including enhancement of employee opportunities, and promotion of individual's unique competencies (Al-Deen \& Hendricks, 2012, p. 82). Overall social media has impacted the economy of Middle-eastern countries in that it has offered support for various businesses; hence, increasing business profits, which end up supporting the economic growth of these countries. This also implies that a larger number of people are online as consumers. In addition, these implications are a relatively novel concept in a society that is highly orthodox in its functioning. Thus, the study of social media and its respective influence on the identity of its population of users remains predominantly unexplored. 
From the above analysis, development of social media in the Middle-east has brought immense prospects for countries emanating from the said region. As such, the growth of social media is foreseen to bring forth more benefits that supersede those discussed herein. The use of social media to propagate mischief such as revolts poses as a challenge for these countries. However, political turmoil cannot be considered to be an evil as it is often the route taken by the masses to fight oppression and bring about much needed social change. Likewise, the influence of social media on Arab youth cannot be judged by the devastation caused by the uprisings that it has been linked to. Instead, its role in shaping the identity of the most dominant segment of Arab society, the youth, needs to be studied.

\section{Theories on Development of Identity}

Social media has provided users with a platform through which they can interact with cultures from the world over. Through social networking sites, friendships and associations may be formed between people who have never met in the real world. This has led to a formation of a global virtual society, one that is not bound by the traditional boundaries of geography and culture. The manner in which users interact in these online or digital 'societies' can have impacts on individual as well as collective identity, which may greatly differ from the influences users experience from their real world surroundings (Willett, 2008, p. 51). In order to analyze the impact of social media on Arab youth identity, two key theories have been identified that illustrate how identities develop. These are: a) Albert Bandura's (1986) Social Cognitive Theory, and b) Festinger's (1954) Social Comparison Theory. The following sections provide an overview of these two theories and how they shape self-image and perception in a social setting. In addition, the concept of Social capital will also be discussed and its relevance to the strong online community bonding being experienced today by users, the youth in particular.

\subsection{The Social Cognitive Theory}

In 1986, Albert Bandura theorized that human behavior is influenced by three main inter-related factors, namely: a) Personal, b) Behavioral, and c) Environmental (Bandura, 1986). Figure-1 illustrates the key factors that influence human behavior. How a person views reality is greatly determined through the influence of these factors. According to the theory, a person relies on their personal experiences and the behavior that they observe in others, to form a view or perception of reality. A person would need to first realize that their behavior is changing as well as the impact this change will have on their lives, if the impact of these observations and experiences is to be positive and motivational. Further, the person would need to customize the model that is being followed so that it better addressed their own situation and then imitate the behavior of the model. Whether a person continues to adhere to the adapted action depends on the success of the change to address their issues once the adaptation has been made.

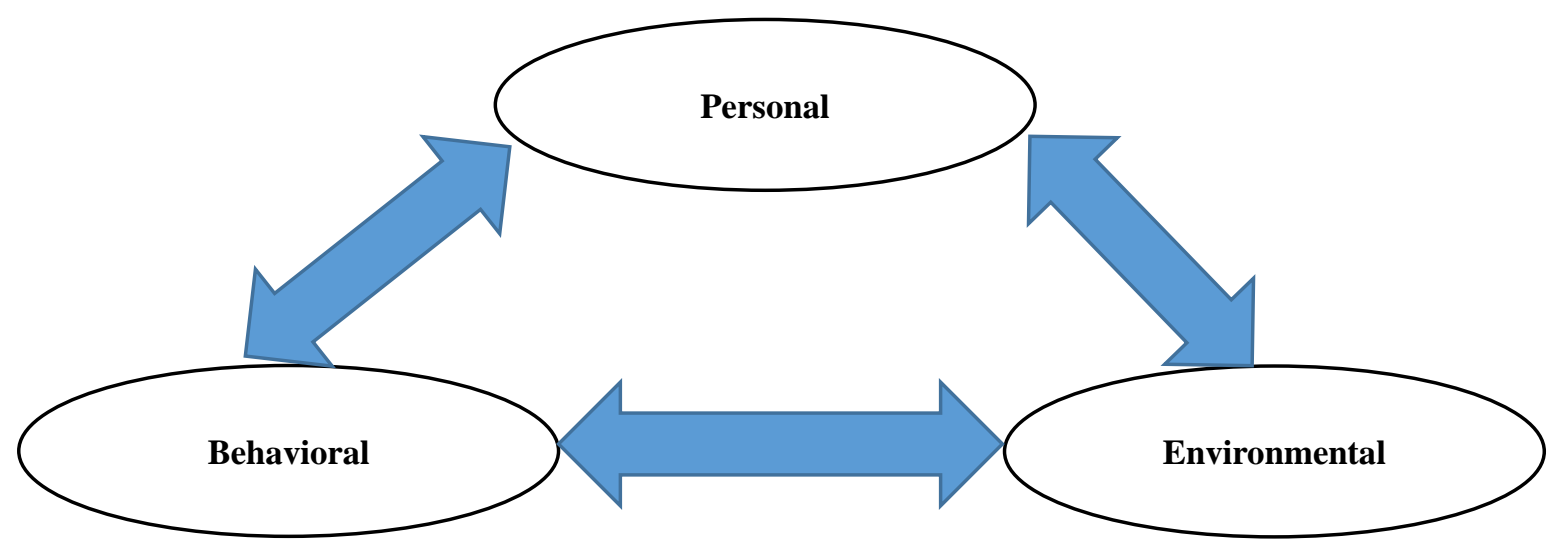

Figure 1. Bandura's social cognition theory (Bandura, 1986)

In this virtual realm, social cognition is influenced by interactions that greatly differ from what a person may be experiencing in their physical surrounding. As a user interacts in a digital environment that varies from their real world social setting, the personal and behavior factors adapt and undergo changes that may not have taken place if the user had been merely interacting with the real world society. The extent to which the digital and real world societies differ dictates the degree of variance of social cognition of the user under both these settings. Despite the extensive use of the social cognition theory to understand social psychology, its implications in the study of the impact of social media on user identity is still relatively under developed.

\subsection{The Social Comparison Theory}

Festinger's Social Comparison Theory first proposed that humans adapt their behavior after drawing comparisons with 
peers or those with whom they interact at a social level (Festinger, 1954). Different forms of appraisals in various contexts are used in the social comparison theory wherein a person compares one's self against related factors. Three kinds of appraisals make up the social comparison theory, namely: a) self-evaluation, b) self-improvement, and c) self-enhancement. In self-evaluation, an individual analyses their own status when compared to others with regards to skills and attributes that are expected of them on a social level. Self-improvement involves the learning of means and ways of improving a skill or attribute that an individual deems to be lacking in comparison to others. Self-enhancement, on the other hand, is an individual comparing skills and attributes to those they consider inferior in order to enhance or maintain self-esteem (Wood, 1989). The individual generally compares with those who are within the same demographic group. Table-1 highlights the various hypotheses on which the theory of social comparison is based:

Table 1. Hypothesis for the Social Comparison Theory

1. There exists, in the human organism, a drive to evaluate his opinions and his abilities.

2. To the extent that objective, nonsocial means are not available, people evaluate their opinions and abilities by comparison respectively with opinions and abilities of others.

3. The tendency to compare oneself with some other specific person decreases as the difference between his opinion or ability and one's own increases.

4. There is a unidirectional drive upward in the case of abilities which is largely absent in opinions.

5. There is nonsocial restraints which make it difficult or even impossible to change one's ability. These nonsocial restraints are largely absent for opinions.

6. The cessation of comparison with others is accompanied by hostility or derogation to the extent that continued comparison with those persons implies unpleasant consequences.

7. Any factors which increase the importance of some particular group as a comparison group or some particular opinion or ability will increase the pressure toward uniformity concerning that ability or opinion within that group.

8. If persons who are very divergent from one's own opinion or ability are perceived as a different from oneself on attributed consistent with the divergence, the tendency to narrow the range of comparability becomes stronger.

9. When there is a range of opinion or ability in a group, the relative strength of the three manifestations of pressures toward uniformity will be different for those who are close to the mode of the group will have stronger tendencies to change the positions of others, relatively weaker tendencies to narrow the range of comparison, and much weaker tendencies to change their position compared to those who are distant from the mode of the group.

From "a theory of Social comparison processes" by L. Festinger, 1954, Human Relations, 7, 117-140.

In traditional societies, a person would be comparing against peers belonging to, and influenced by, the same societal factors. However, in the virtual world, the interactions are between people belonging to societies from around the world. Hence, a user is exposed to a diverse set of viewpoints that, over time, can lead to different standards of comparison. Youth with regular exposure to social media interactions constantly compare themselves with peers they have met online, who may not necessarily belong to their real-world societal makeup (Jay, 2012).

\subsection{Human Agency and Social Capital}

The virtual communities formed through social networking sites consist of bonds and relationships, the strength of which had not been fathomed until very recently, when the true impact of social media of day-to-day lives of users has been noted. Within this virtual society, similar to real world societies, there are those who influence others, as well as those who use connections with other influencers. This is a form of human agency (Code, 2013, p. 38). In social networks, this agency can be used for a variety of purposes including marketing, advertising, exchanging views, organizing events or, even bringing about social change. For a user to effectively build and utilize agency, they would first need to build social capital.

Before pursuing analysis, a fundamental understanding of social capital is first needed, both in its offline and online modes. The term broadly indicates the resources collected through relationships among different people. From this definition, the concept of social capital is flexible across various applications, with fluctuating definitions and coexisting functions as both cause and effect. Wacquant and Bourdieu (1986) have placed the definition of social capital to represent the sum of resources, either actual or virtual, "which accrue from membership in a group" and "are linked to possession of a durable network of more or less institutionalized relationships of mutual acquaintance and recognition" (p. 21). These 
relationships offer resources that differ not just in function but even form, depending on the nature of the relationships (Ellison, Steinfield, \& Lampe, 2007).

Social capital has connections to different positive social outcomes like improved public health, lower rates of crime as well as effective economic markets. Judging from the panoply of various social capital metrics, a noticeable waning in this critical resource has been sustained for several consecutive years. With the decline of social capital, a community is likely to experience greater social disorder, lesser civil activity participation and more distrust among members of the community. Contrarily, if social capital increases, corresponding improvements to a community's unity and ability to pursue collective actions independent from outside influences are enriched. In some settings social capital can be employed for adverse intentions, but generally it is considered to promote favorable interactions across members of a given social community (Valkenburg \& Peter, 2009).

\section{Growth of Social Media in the Middle-East}

As discussed earlier, the growth if social media usage amongst the Middle-eastern youth and the increasing discontent and political upheaval took place at about the same time. It has been discussed that the Arab youth have taken into social networking with great zeal. In order to understand the influence that social media has on Arab youth identity, it is important to evaluate the degree to which it has penetrated the day to day lives of this segment of the society. Which countries have seen the most swift and widespread adoption of social media? Which social networking sites have been most popular amongst the youth? What segments within the youth use social media the most? What are the purposes that the youth uses social media for? These are some of the critical questions that this section seeks to find answers to.

Both social media and similar networking platforms have enjoyed a thriving user base throughout Middle-eastern and North African countries during previous years. As on July 2011, over eight million users of Facebook existed solely in Egypt (SocialBakers, 2011), of which seventy-eight (78) percent were comprised of users between the ages of 15-29 years old (Interactive Middle East, 2011). As a direct comparison, Twitter maintained an Egyptian user base of approximately just one million users during March of 2011. However, analysis of the site's activity shows a near doubling of this population when measured during and promptly after the revolution itself (Saqer, 2011).

Social media use in Saudi Arabia has grown exponentially. In the years 2011 to 2012 alone, users of key SNSs such as Twitter, YouTube, and Facebook have grown manifold. According to a survey conducted by The Social Clinic, Saudi Arabian youth have particularly taken to Twitter, with over 3 million users in 2012 - an astounding three thousand (3000) percent growth over 2011, making it the fastest growing Twitter base in the world. Fourty-five (45) percent of these users are women. The site is predominantly used by the youth, with the largest user group consisting of 25-34 year olds, while the second largest group is of 18-24 years (The Social Clinic, 2013). Figure-1 is an info-graphic, which reveals the tremendous growth in the use of Twitter and its influence on Saudi Arabian youth.

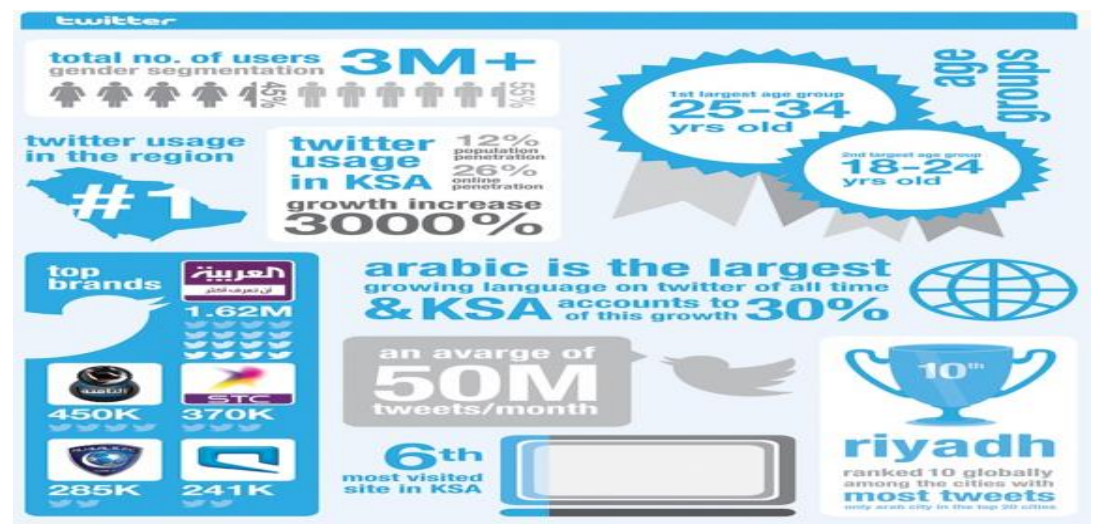

Figure 2. Twitter Trends in Saudi Arabia 2012 (The Social Clinic, 2013) 
Similar success has been witnessed by YouTube as well as Facebook. At 920 million views per day in 2012, Saudi Arabia is the highest YouTube viewership in the world, with a one hundred and nine (109) percent growth over 2011. With 6 million active users, Facebook is the Kingdom's third most popular site. While the age groups using the site are the same as Twitter, only thirty (30) percent of Facebook users are women (The Social Clinic, 2013). Figure-2 is an info-graphic, which illustrates the growth and influence of YouTube and Facebook in Saudi Arabia.

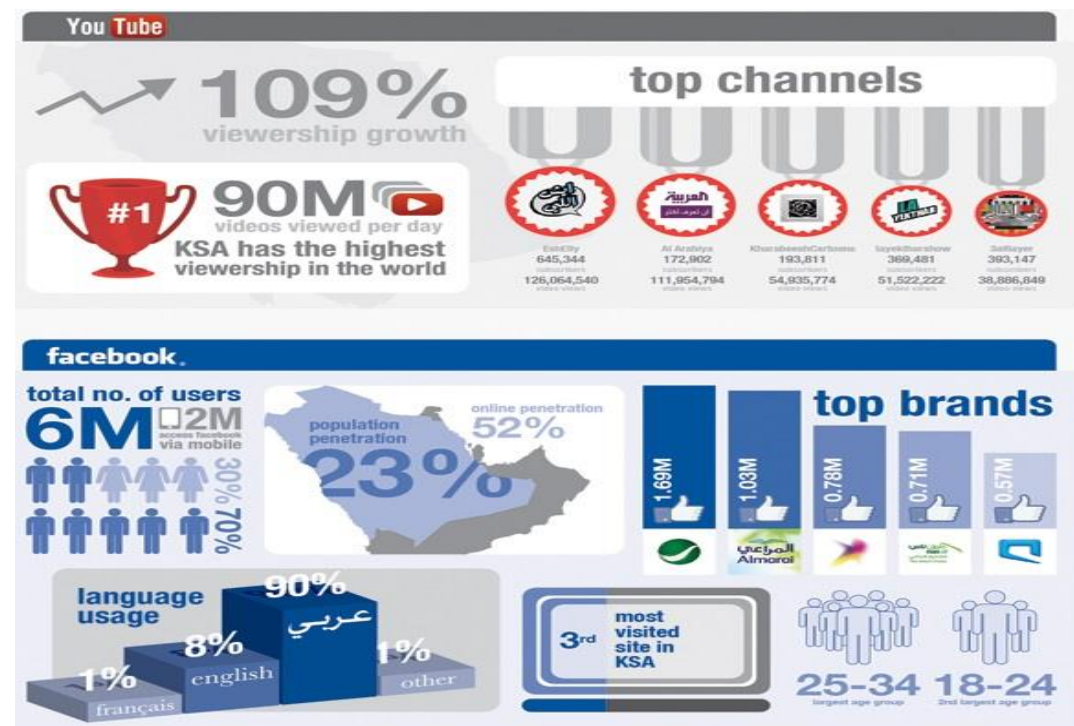

Figure 3. You tube and Facebook Trends in Saudi Arabia 2012 (The Social Clinic, 2013)

It should be noted that thirty (30) percent of Twitter 'tweets' and ninety (90) percent of Facebook updates are made in the Arabic language. This is a very important statistic as it implies that even those who are not active users of the sites but have internet access can view and understand the messages. Considering that a small percentage of women have access to higher education and fewer still speak the English language, communications in Arabic give them open access to opinions of fellow citizens (The Social Clinic, 2013).

The Commission to Promote Virtue and Prevent Vice or Hai'a is Saudi Arabia's moral police, literally. It consists of religiously qualified men who patrol public places and are empowered to prevent immoral behavior in public. There have been little to no regulations or governance of the Hai'a and there have been several accounts of its members abusing their authority. With over sixty-six (66) percent of the country's population consisting of those below 29 years of age, the brutal assaults by the Hai'a on the youth gained tremendous public view from exposure due to social networking outlets, especially Facebook and Twitter (Lief, 2013). Without extensive incorporation of social media, these incidents would have been mostly unreported considering the extent of media censorship in the nation.

\section{Influence of Social Network on Youth}

It has been thus far discussed that social media has seen widespread acceptance amongst the Arab youth, who have used it to form online communities, specifically on Facebook. Through the evaluation of the key theories mentioned in the previous section, it has been assessed that these virtual communities can have the same impact in the context of social cognition and social comparison. In other words, these virtual communities can affect the development of user identities in a manner similar to that of real world societies. Further, it was noted that not only do online associations have power relationships, but they also serve as a base of resources. This section delves into the specific influences that social media has on youth. Beginning with a review of literature that has established that social media does influence youth identity in general, it will focus on the effects that social media has had on Arab youth in particular. What are the unique challenges faced by this segment of the Arab society and how has the influence of social media affected these aspects? How has it influenced the perception of concepts of gender equality and liberalization amongst the youth? In view of the social comparison and social cognition theories, how do the reactions of the youth towards social media reveal a change in identity? These are some of the critical questions that will be explored in this section. As Facebook maintained a more compelling position in the social and political developments across the region, specific focus will be given to the impact of this social networking site.

\subsection{General Impact of Social Media on Youth}

Since the onset of technological devices and gadgets during the 1990's, there has been a growing interest in how mobile telephony, the Internet, and other information and communication technologies (ICT) are being utilized by the different 
age groups in our global society (Oksman). The scope of these studies is often on the social functions of technologies in shaping people's lives (Oksman). Most of these studies center on the youth segment of the population since they are presumed to be the ones who mainly utilize technologies in their studies, work and leisure activities. The youth are considered the most active part of the utilization of these technologies, and this has become recognized as a social phenomenon (Oksman, 2005).

Tapscott (2009) opined that the "Next Generation" is best understood by studying the young generation - those who are between 11 to 30 years old, who are constantly using technologies to do the following: texting, downloading music, uploading videos, watching a movie, and social networking on various sites like Facebook or MySpace. The author suggests that the Baby Boomer and Gen X-er must learn how to live in a digital age by following the young generation.

The study is an expensive and an extensive survey of more than 11,000 young individuals. The main argument of Tapscott is that the activities and the ways of thinking of the young generation will shape how the digital age will evolve in the future. Interestingly, the author described the youth as intelligent individuals who have new and dynamic ways of thinking, interacting, socializing, and working. They are described to be techno-smart and are at the forefront of changing all aspects of the digital society.

These studies reveal that social media, in general, has been most widely accepted by the youth around the world. It is their swift adoption of this communication technology that has spurred other segments of the society to accept it too, giving social media a much broader user base than it initially had. However, the youth continue to be considered the primary and most active users of social media.

\subsection{Impact of Social Media on Arab Youth}

According to research conducted by the Arab Social Media Report (2011), the expansion of social networking and Web 2.0 applications is dynamically increasing in the Arab region. It attributes this to the generally youthful demography of the region, where individuals between 15 and 29 years old comprise about one third of the whole population. With the multiplied growth of social networking, specifically in the youth segment, it is forecasted that social media will be a potential instrument to shape civil engagement in the region. It is also expected to prompt social integration and develop more jobs and labor opportunities, prospects for entrepreneurship and development, among others (Mourtada \& Salem, Facebook Usage: Factors and Analysis, 2011).

The youth in this region has a unique set of challenges that defines them as the 'Arab Youth'. There are high levels of unemployment amongst the youth who also form a majority of the population. They do not identify well with the dictatorial regimes that govern Arab nations and have shown an inclination towards a more liberal, if not democratized government. The youth has been associated with prompting the great political instability in the region and has even been linked to terrorism(Afifi, 2011, p. 8). They are extremely interested in participating in bringing about social; change through civic engagement, however, they lack the right opportunities to participate (Fitouti, 2011, p. 18).

It is well known that social media encourages the distribution of many forms of information. In the case of the Arab youth too, it facilitated open sharing of opinions, experiences and aspirations, not only amongst the Arab youth, but also with youth from around the world. This interaction has led to a significant change in youth mind-sets. In fact, there now exist organized youth groups that use the avenue of social media to continue this process of social and civic change by influencing other users (Mourtada \& Salem, 2012, p. 269). In other words, they are using human agency to influence others, while relying on positive social capital to retain trust amongst followers. By constantly sharing information and opinions from around the world to highlight the social grievances existing within the region, social media has enabled the youth to identify the degree of oppression that they are facing. Over time, through social cognition and social comparison, being 'the oppressed' becomes a part of the youth identity (Kraidy \& Khalil, 2008, p. 341).

This phenomenon will impact across the Middle-east and North Africa (MENA) region as they share a common social, civic and cultural background. However, the degree with which a given nation's youth's identity is influenced by social media would depend on various aspects including levels of education, economic development, standards of living, and, of course, degree of exposure to social networks. For example, while the entire region is highly conservative about issues pertaining to women's rights and liberation, some are more conservative than others. As a result, the right demanded and enjoyed by women in different nations of the region will also differ (Mourtada \& Salem, 2012, p. 271).

There have been studies that support this aspect that social cognition and social comparison will lead to differed instances of impact that social media has had, or is having, on the youth of a given country. In a recent study, De-Long Bas (2011) shows that there are various lessons to be learned from the successful use of social media in encouraging political and social change. Initially, information technology is evidently being used by a wide range of people. This has a global impact. It also shows that women have found a new channel to air out their social concerns. They have used social media to be united and fight against their oppressors. In Cairo, for instance, women use mobile telephones to either send text 
messages or tweets to social networking sites to relay reports of sexual harassment which are updated in the actual time (DeLong-Bas, 2014).

In the Dubai School of Government report (2012) addressing social media, it was seen that Middle-eastern women's participation in social and media technology still lags behind their male counterparts. Their participation also lags behind the women in other parts of the world. The August 2011 report showed some of the specific difference. To illustrate, Middle-eastern women only comprise one third of the region's Facebook users while, in the rest of the world, about half of the users are women. Middle-eastern women use social media primarily as a news source (Messieh, 2011). As a result of the demographic and cultural hurdles that are unique to Arab women, the impact of social media on their identity through social cognition and comparison may not be as swift or deep as in the case of their male counterparts. Further, the social injustices faced by women also greatly differ from that of men and hence they will have different notions and standards of oppression (Mourtada \& Salem, 2012). The purpose for which social media is used by the two genders also dictates the degree if influence it will have on the development of their identities.

\subsection{A Focus on Facebook}

The younger generations tend to utilize the Internet as a common method of communication. Facebook has witnessed unprecedented growth since its inception in the year 2004. Till the year 2011, the social network boasts of 500 million active users. Owing to the massive proliferation of Facebook and the considerable activity among young adults, it is necessary to comprehend the significant capability of this social networking medium. The use of Facebook is responsible for affecting other kinds of communication along with development and maintenance of relationships (Sabbagh, Mourad, Kabbara, Shehadi, \& Samman, 2012).

There are plenty of research opportunities in the field of social networking including the analysis of the effect of Facebook on interpersonal friendships. Through the determination of the impact of usage of the social network site, it is possible to help young adults use the page as well as other emerging kinds of interpersonal communication in an effective manner. Facebook usage can be defined as possessing an active Facebook page and account. Interpersonal friendships can be defined as relationships of the non-romantic nature. CMC or Computer mediated communication can be referred to the type of communication that is possible through a technological medium (Valkenburg, Peter, \& Schouten, 2006).

Most people use Facebook since their peers are members of the website. Therefore, it is a necessity to maintain their social lives. People, especially teenagers, are motivated to go online since they have friends who do the same. The internet has now become an additional place where it is possible for people to go and manage their off line relationships. Interactions that take place on the internet are not hampered by geographical location but face-to-face communication needs physical proximity.

Maintenance of relationships and information-seeking are common motivators for people to join Facebook and other social media sites. Facebook permits its users to gather information regarding their Facebook friends via public information shared on their user profiles and wall posts. Researchers have indicated that an essential Facebook activity is to reinforce societal connections in existence and maintain friendships of the long distance variety. Facebook can help students take care of their present connections with friends from back home and high school. As these relationships are often prone to physical separation, forming an online connection can help students adjust.

Self-disclosure, an essential portion of relationship development, is one of the most important motivating factors for joining Facebook. It promotes trust and information-sharing. Instant messaging enables adolescent users to disclose issues they may not normally convey in a more personal setting, and also provides a release to share personal issues with friends and colleagues that might otherwise be impossible due to physical real estate, or the presence of parents or guardians nearby. This process allowed users to reinforce their existing friendships (Valkenburg \& Peter, 2009). Facebook users exhibit some specific traits of personality. Introverts have been found to have a higher chance than extroverts to use the overall internet but extroverts seem to log in more hours on social networking websites. The self-esteem of a person is greatly subject to the expression of feedback gathered on the virtual profile of the person (Wilson, Fornasier, \& White, 2010).

\section{Social Media and the Arab Spring}

The review of literature so far has revealed that social media has a definite impact on youth identity. Based on the theories of social cognition and social comparison, it has been illustrated how social media has had a unique influence on Arab youth, broadening their understanding of social concepts of liberalization and gender equality, empowering them to share and express their grievances, and motivating them to take actions towards bringing about a change. As mentioned earlier, the mass adoption of social media by the Arab youth was an immediate precursor to the Arab Spring revolutions. Immediately after the revolutions took place, social media was said to have facilitated the revolts by acting as an effective means of communication. Through this paper, it has been illustrated that social media was not just giving the Arab youth 
a medium of communication, but it was affecting their identity in ways that had not been understood at the time. In this section, the aspect portrayed by social media during the Arab Spring will be re-evaluated in light of the findings of the preceding discussion of youth identity. This discussion will highlight not only the larger function of social media in this timeframe, will also anticipate the role that it will continue to play through its constant influence on youth identity.

Social media and networking sites have gained increasing predominance as a simultaneous communication methodology and distribution chain of information over the past ten years. It has sustained a tremendous influence throughout a population's communication mannerisms, and its influence is not limited to a specific generation. Due to its direct nature of the views and opinions shared through social networking sites, social media has become a trusted source of information in an age where conventional media has been known to fall prey to lobbying. While the adoption of social media varies from nation to nation, its impact on society at large and its fast-paced growth is undeniable. While the internet had opened the doors to global communications, social networking sites or SNSs have constantly created avenues for direct interaction at a frank, personal level.

Middle-eastern countries have been the scene of great political tumult in recent times. From the evidence available, SNSs are strongly considered to possess major roles in the swift dispersion of crucial information to the masses that contributed to the uprisings. However, while chaos reigned in countries such as Egypt, Libya, Yemen and Tunisia, in addition to unrests of a lesser degree in Kuwait, Bahrain, Jordan, Iraq and Syria, Saudi Arabia remained relatively peaceful and even passive. This absence of social unrest has been greatly attributed to the stringent internet censorship laws that are in place in the Kingdom. At the same time, the cause of peace in Saudi could also be the result of the acceptability of the government in the general public view. The Saudi Arabian government is quite open about its censorship rules and, in fact, the citizens of the country have been the main enforcers of censorship on the internet. SNSs, however, have remained an exception with limited censorship.

The capability to publicly express individual opinions and disburse broadcasts anonymously has enabled SNSs to operate in crucial roles across major political events in recent years, including the Arab Spring. Both technology and social media are heavily dependent on their encompassing demographics, which is especially impacted by the 55-70\% population of those in the Middle-east under the age of 30. These statistics provide a substantial stimulus to encourage the use and incorporation of both social media and other SNSs in regions such as these. However, it is important to note that social media was not the galvanizing factor for the uprisings occurring in Egypt or Tunisia; these were instead a result of overarching vexation with an oppressive and inflexible government. With this in mind, SNSs still performed significant functions in the distribution of news surrounding various atrocities and subsequent demonstrations by the people that ultimately united them together in their shared objectives.

In the specific instance of Tunisia, the coverage of Mohamed Bouazizi setting himself ablaze in SidiBouzid was quickly transmitted all over the world during December, 2010. Both Facebook and Twitter served as common platforms for discussing dissentions, which marshaled even more organizations of analogous events throughout the region. Due to their global audiences, SNSs emboldened distant Egyptian youth to assemble their own demonstration at Tahrir Square. In support of this effort, a Facebook page entitled "Day of Revolution" was constructed, identifying the location of the protest and serving to connect over 90,000 subscribers to its communication broadcasts (Fahim, 2011). Similarly, the awareness of such protests stirred up many other outcries in other countries, leading to uprisings in Yemen, Jordan, Syria, Libya, Iran, Bahrain, Kuwait and Algeria (Mlight, Pulham, \& Torpey, 2012).

A report revealed that between January to March 2011, the most popular hashtags among Arab Twitter users were related to the Arab Spring, with \# egypt gaining 1.4 million tags, \#jan25 - which was the official beginning date of the Egyptian revolution - got 1.2 million tags, \#libya gained 990,000, \#bahrain got 640,000 tags, and \#protest was mentioned 620,000 times (Interactive Middle East, 2011). 63\% of those who had participated in the Egyptian protests had relied on social media to keep updates on the latest news about the revolution (Saqer, 2011).

Egypt manages a unique constitution of demographics, with half its population younger than 25 years old, and one-fifth between the ages of 15-24 (Roudi-Fahimi, El Feki, \& Tsai, 2011). Analysis of statistics from the Egyptian Revolution revealed that the vast majority of participants were younger than 29 years of age. Due to the large rate of unemployment, the population of youths were afflicted by adverse conditions, including low standards of living and corruption in various sectors. A 2009 survey of Egyptian Youth aged between 15-29 years revealed that they were highly concerned about several social issues that were rampant in their country. Table 2 illustrates that the youth had several reasons to protest. 
Table 2. Percentage of young people reporting on issues very important for Egypt, 2009 (Roudi-Fahimi, El Feki, \& Tsai, 2011)

\begin{tabular}{l|c}
\hline \multicolumn{1}{c|}{ Social Issue Reported as Very Important } & Percent Ages 15-29 \\
\hline Poverty reduction & 92 \\
\hline Fighting rising prices & 90 \\
\hline Fighting corruption & 88 \\
\hline Reforming the education system & 86 \\
\hline Strong defense forces & 86 \\
\hline Reforming the heal care system & 85 \\
\hline A high level of economic growth & 78 \\
\hline Protecting freedom of speech & 75 \\
\hline Protection of political rights & 64 \\
\hline People have a large role in government & 63 \\
\hline Political leaders with stronger religious beliefs & 53 \\
\hline
\end{tabular}

The causes of revolution across the countries of Egypt, Tunisia, and Libya maintained notably unique motivations. In Tunisia, uprisings consisted largely of destitute rural masses, while in comparison the Egyptian demonstrations were primarily constituted by youth of the urban subculture. In contrast to each of these, the Libyan insurgency was composed of those from more tribal origins (Anderson, 2011). Regardless of the revolution's individual demographics, the influence maintained by social was universal throughout.

The most important aspect of social media here is the ability of protestors and revolutionaries to share information and news with not just local users but the international community too. Before the widespread adoption of social media among the youth, it had been common for dictatorial regimes to suppress revolts at their roots. Activists and opposition leaders would either be threatened or assassinated in order to instill fear amongst their followers. With the traditional media such as newspapers, television and radio networks being general run by the government, the 'filtering' of news was common. This was done to ensure that acts of crime, atrocities and subjugation were not relayed to people within the country as well as across borders. If the people did not know that their suffering was shared, they would not have the motivation to come together to fight for a common cause.

With the self-emulation of Mohamed Bouazizi may have acted as a trigger for the protests in Tunisia, but it was the news of the mass dissent against the government in that land being communicated swiftly across Egypt that led the Egyptian youth to realize that oppression knew no boundaries and neither did revolution. As news of protests in Tunisia were read across social media networks, this may have inspired the Egyptian as well as other Arab youth to take action against their governments in order to win their rights. In a traditional revolt, government authorities would have been able to curb the revolt by merely ensuring that activists never had the opportunity to communicate with each other, plan protests and carry them out. Even if people did manage to gather at a public place, they would have been dispersed, by force if necessary. The 1989 Tiananmen Square massacre in Beijing, China, serves as the perfect example of such extreme government actions (Schiavenza, 2013).

However, while 24 years ago, it may have been possible for a government to mercilessly squash a revolt at the cost of great human loss, social media acts as a modern day whistleblower at a global level. When the protest at Tahrir Square was announced and thousands of Egyptians converged at the site named after the 1952 revolution that changed Egypt from a monarchy to a republic, social media was used to spread minute-by-minute news to the international community. With the world anticipating a Tiananmen like scenario, the Egyptian government was constantly under immense international pressure and scrutiny to ensure that human rights of the protesters were not violated. As a result, although there were several fatalities, the protests did not turn into an outright massacre. Hence, social media's importance in the success of the Arab revolutions is clearly apparent.

It should also be noted that the Arab Spring did not affect the entire Middle-east. While the revolutions in Tunisia, Egypt and Libya resulted in the toppling of their respective administrations, the protests in other countries such as Yemen, Bahrain, Syria and Iraq yielded no result. The fact that Saudi Arabia remained more or less undisturbed by the Arab Spring has raised many questions. With the exception of one protest in the city of Qatif that was swiftly controlled and extinguished, the Kingdom did not see any protest of note. Further, although several groups and pages cropped up on Facebook called for protests, these did not receive any sizeable support for fellow citizens. While this has been attributed to governmental censorship of the internet and the moral policing of SNSs, some also believe that complacency and fear of being witch hunted may have prevented the masses from coming out in support for social change. In other words, it has been said that the people were either not truly concerned about bringing about political change, or they were concerned by feared governmental retaliation if they supported these calls (Bradley, 2011). However, a survey conducted in Egypt and 
Tunisia found that sixty (60) percent of users believed that banning of social media had contributed to the outbreak of the revolution(Dubai School of Government, 2012). It is often seen that further oppression of those who are protesting against oppression in the first place can cause the masses to ignite and for an all-out revolution to break out. It should be noted that, if there was sufficient discontent amongst the Saudi Arabian people, and the government was, in fact, censoring social networks then, as in the case of Egypt, there should have been an outbreak in the Kingdom too. However, as Bradley noted, since there was no significant reaction from the Saudi Arabian people, it can only mean that the people either do not want political change or are afraid to stand up for it.

\section{Conclusion}

Social media is acting as the harbinger of change. With a majority of the Middle-eastern population consisting of youthful populations, technology and social networking sites have gained fast paced influence on the accessibility and sharing of information. Beginning in 2011, the widespread incorporation of social networks, namely Twitter, Facebook, and YouTube, has increased substantially with modern electronic devices and cell phones. This technological revolution has also been observed to play pivotal roles in societal and political events especially during the Arab Spring demonstrations across many Middle-eastern countries, particularly in Egypt and Tunisia. Such uprisings can produce significant influence, even bringing down entire administrations (as in the case of Egypt). Based on the Social Cognition Theory and the Social Comparison Theory, those segments of the youth that have regular and purposeful interactions with others through social networking sites will develop identities that differ from those without similar access. As such, social media can be said to be an amplifier for social cognition and comparison, particularly in the context of social change and civic engagement situations that the Arab youth finds itself today.

It is probably in acknowledgement of the power of social media that Saudi Arabia's religious police have been labeling social networking sites as the path to evil and sin. While the government does not openly ban such sites, there is a degree of censorship of what can be posted and shared as well as extensive moral policing conducted not only by authorities but also by users who agree with the rules imposed by them. This could possibly be the reason that, while social media helped protests in several countries during the Arab Spring, Saudi Arabia has remained largely unaffected. This mass censorship may be considered a violation of the freedom of speech and expression, but it is extremely common in the Arab world. This widespread censorship of media applies all the more to social media and networking sites. Although these sites are not banned or censored in Saudi Arabia, the content is highly subject to moral policing not only on the part of religious groups and authorities, but the common users as well.

In summation, the underlying determination of those occupying tormented and tyrannized nations supplies the essential drive for revolution. The role of social media in such situations is nothing more than a supporting keystone, in which social demonstrations can be conceived and accomplished. The global population of those subscribed prevents dictatorships from diminishing or even masking the harrowing events occurring, such as mass murdering of protesters to extinguish uprisings. In addition, publicized demonstrations also carry the additional influence to spark revolutions across distant lands. The governments of various Middle-eastern countries, including Saudi Arabia, are increasing their awareness of these platforms' potentials, and are introducing constructive outlooks toward employing them for positive social development. As the growth of social media usage amongst the youth of the region continues, so will its influence on the shaping of their identities. The change may be in the form of a desire for greater social justices or, in the case of women, greater gender equality. In any case, social media will persist in playing a major role in forming the new Arab youth identity and facilitating social and civic change in the process.

\section{References}

Afifi, R. (2011). Youth Challenges in Social Transformations in the Arab Region. In Arab Youth: Civic Engagement Economic Participation (pp. 8-15). Beirut, Lebanon: UNESCO Regional Bureau.

Al-Deen, N., \& Hendricks, J. A. (2012). Social Media: Usage and Impact. Lanham: Lexington Books.

Anderson, L. (2011). Demystifying the Arab Spring: Parsing the Differences Between Tunisia, Egypt, and Libya. Foreign Affairs, 90(3), 2-7.

Bandura, A. (1986). Social Foundations of Thought and Action: A Social Cognitive Theory. Englewood Cliffs, NJ: Prentice Hall.

Blight, G., Pulham, S., \& Torpey, P. (2012, January 5). Arab Spring: an interactive timeline of Middle East protests. Retrieved from http://www.guardian.co.uk/world/interactive/2011/mar/22/middle-east-protest-interactive-timeline

Bradley, J. R. (2011, October 13). Saudi Arabia's invisible hand in the Arab Spring. Retrieved from http://www.foreignaffairs.com/articles/136473/john-r-bradley/saudi-arabias-invisible-hand-in-the-arab-spring

Code, J. (2013). Agency and Identity in Social Media. In Warburton \& S. Hatzipanagos (Eds.), Digital Identity and 
Social Media (pp. 37-57). Hershey, PA: Information Science Reference - IGI Global. https://doi.org/10.4018/978-1-4666-1915-9.ch004

DeLong-Bas, N. J. (2014, March 3). Oxford Islamic Studies Online. Retrieved from http://www.oxfordislamicstudies.com/Public/focus/essay0611_social_media.html

Egypt Facebook Statistics. (2011). Retrieved from http://www.socialbakers.com/facebook-statistics/egypt

Ellison, N. B., Steinfield, C., \& Lampe, C. (2007). The benefits of Facebook "friends': Social capital and college students' use of online social networking sites. Journal of Computer-Mediated Communication, 12(4), 1143-1168. https://doi.org/10.1111/j.1083-6101.2007.00367.x

Facebook statistics in the MENA region. (2011, February 16). Retrieved from www.interactiveme.com/index.php/2011/02/facebook-statistics-in-the-mena-region

Fahim, K., \& El-Naggar, M. (2011, January 25). Violent clashes mark protests against Mubarak's rule. Retrieved from http://www.nytimes.com/2011/01/26/world/middleeast/26egypt.html?pagewanted=all\&_r=0

Festinger, L. (1954). A Theory of Social Comparison Processes. Human Relations, 7(2), 117-140. https://doi.org/10.1177/001872675400700202

Fitouti, S. (2011). The Arab youth torn between a strong desire for active civic engagement and lack of consistent opportunities. In Arab Youth: Civic Engagement and Economic Participation (pp. 16-18). Beirut, Lebanon: UNESCO Regional Bureau.

Howard, P. N., \& Hussain, M. M. (2013). Democracy's fourth wave: Digital media and Arab Spring. London: Oxford University Press. https://doi.org/10.1093/acprof:oso/9780199936953.001.0001

Jay, M. (2012, March 30). Just say no to Facebook social comparisons. Retrieved from http://www.psychologytoday.com/blog/the-defining-decade/201203/just-say-no-facebook-social-comparisons

Kraidy, M. M. (2008). Youth, media and culture in the Arab world. In K. Drotner \& S. Livingstone (Eds.), International handbook of children, media and culture (pp. 330-344). London: Sage. https://doi.org/10.4135/9781848608436.n21

Lief, L. (2013, May 23). With youth pounding the kingdom's gates, Saudi Arabia begins religious police reform. Retrieved

from http://news.yahoo.com/youth-pounding-kingdoms-gates-saudi-arabia-begins-religious-162447616.html

Messieh, N. (2014, March 3). Social Media: A double edged sword for the empowerment of women in the Middle East. Retrieved from http://thenextweb.com/me/2011/12/26/social-media-a-double-edged-sword-for-the-empowerment-of-women-in-the -middle-east

Nabi, R. L., \& Oliver, M. B. (Eds.). (2009). The Sage Handbook of Media Processes and Effects. Los Angeles: SAGE.

Oksman, V. (2006). Young People and Seniors in Finnish 'Mobile Information Society'. Journal of Interactive Media in Education, 2006(2), Art. 2. http://doi.org/10.5334/2006-3

Roudi-Fahimi, F., Feki, S. E., \& Tsai, T. (2011, February). Youth revolt in Egypt, a country at the turning point. Retrieved from http://www.prb.org/Articles/2011/youth-egypt-revolt.aspx

Sabbagh, K., Mourad, M., Kabbara, W., Shehadi, R. T., \& Samman, H. (2012). Understanding the Arab Digital Generation. Beirut, Lebanon: Booz \& Company.

Sakr, N. (2004). Women and Media in the Middle East: Power Through Self-Expression. London: Taurus.

Salem, F., \& Mourtada, R. (2013). Arab Social Media report - Social Media in the Arab World - Influencing Societal and Cultural Change? Dubai School of Government, 2(1), 1-29.

Saqer, G. (2013, June 4). 63\% of demonstrators during the Egyptian Revolution used the internet as the only news source. Retrieved

from http://arabcrunch.com/2011/07/first-report-about-the-internet-and-the-revolution-in-egypt.html

Schiavenza, M. (2013, June 4). How China made the Tiananmen Square Massacre Irrelevant. Retrieved from http://www.theatlantic.com/china/archive/2013/06/how-china-made-the-tiananmen-square-massacre-irrelevant/276 $500 /$

Stewart, D. (2012). The Middle East today: Political, Geographical and Cultural Perspectives. Sydney: Routledge. https://doi.org/10.4324/9780203828960 
The State of Social Media in Saudi Arabia 2012. (2013, January 6). Retrieved from http://www.thesocialclinic.com/the-state-of-social-media-in-saudi-arabia-2012-2/>.

Valkenburg, P. M., \& Peter, J. (2009). Social Consequences of the Internet for Adolescents: A Decade of Research. Current Directions in Psychological Science, 18(1), 1-5. https://doi.org/10.1111/j.1467-8721.2009.01595.x

Valkenburg, P. M., Peter, J., \& Schouten, A. P. (2006). Friend networking sites and their relationship to adolescents' well-being and social self-esteem. Cyberpsychology and Behavior, 9(5), 584-590. https://doi.org/10.1089/cpb.2006.9.584

Willett, R. (2008). Consumer Citizens Online: Structure, Agency, and Gender in Online Participation. In D. Buckingham (Ed.), Youth, Identity, and Digital Media (pp. 49-70). Cambridge, MA: The MIT Press.

Wilson, K., Fornasier, S., \& White, K. M. (2010). Psychological predictors of young adults' use of social networking sites. Cyberpsychology, Behavior and Social Networking, 13(2), 173-177. https://doi.org/10.1089/cyber.2009.0094

Wood, J. V. (1989). Theory and research concerning social comparisons of personal attributes. Psychological Bulletein, 106, 231-248. https://doi.org/10.1037/0033-2909.106.2.231

\section{Copyrights}

Copyright for this article is retained by the author(s), with first publication rights granted to the journal.

This is an open-access article distributed under the terms and conditions of the Creative Commons Attribution license (http://creativecommons.org/licenses/by/4.0/). 